\title{
Chronic hepatitis C in Western Canada: A survey of practice patterns among gastroenterologists in Alberta and British Columbia
}

\author{
Rohit Pai $M D^{1}$, Alnoor Ramji $M D^{1}$, Samuel S Lee $M D^{2}$, Winnie W Wong $M D^{3}$, Eric $M$ Yoshida $M D^{1}$
}

R Pai, A Ramji, SS Lee, WW Wong, EM Yoshida. Chronic hepatitis $\mathrm{C}$ in Western Canada: A survey of practice patterns among gastroenterologists in Alberta and British Columbia. Can J Gastroenterol Hepatol 2014;28(1):e1-e4.

OBJECTIVE: To survey gastroenterologists in British Columbia and Alberta with regard to awareness of chronic hepatitis C virus (HCV) management and practice patterns among physicians who treat and do not treat $\mathrm{HCV}$-infected patients.

METHODS: An anonymous two-page mail survey was distributed to actively practicing adult gastroenterologists in British Columbia and Alberta. Among physicians who treated HCV patients, respondents answered assessment of fibrosis pretreatment, measurement of rapid virological response, prescription of protease inhibitors (PIs), barriers to using these agents and referral patterns. For those who did not treat $\mathrm{HCV}$, referral of patients for treatment and to whom was assessed.

RESULTS: Seventy-seven of 166 individuals completed the survey (46\% response rate). Most (49\%) practiced in academic or large community (42\%) settings. Chronic liver disease comprised $<25 \%$ of individual practice in $71 \%$. Forty-eight $(62 \%)$ treated HCV and twothirds prescribed a PI. Barriers to prescription included unfamiliarity (six of 16), lack of allied health (five of 16) and few suitable patients (seven of 16). Pretreatment liver biopsy was performed by 33\% (16 of 48 ) and $69 \%$ (33 of 48) used noninvasive measures. Rapid virological response was measured in $83 \%$ ( 40 of 48 ). Referral patterns changed in $46 \%$ (22 of 48) of physicians who treated HCV. All respondents who did not treat HCV referred patients for consideration, with 90\% (26 of 29) made to hepatologists.

CONCLUSIONS: Chronic liver disease comprised $<25 \%$ of practice in the majority of surveyed respondents. Among those who treated $\mathrm{HCV}$, one-third have not prescribed a PI. Barriers to prescription and referral pattern changes are noted by those currently treating patients with HCV infection.

Key Words: Barriers; Guidelines; HCV; Practice; Rapid virological response; Referral; Survey

\footnotetext{
In Canada, an estimated 240,000 individuals are chronically infected 1 with hepatitis C virus (HCV) (1). Many of these patients are asymptomatic and at risk for developing decompensated cirrhosis, hepatocellular carcinoma and need for liver transplantation (2). Of the six $\mathrm{HCV}$ genotypes, genotype 1 is most prevalent in North America and was associated with rates of sustained virological response (SVR) of $40 \%$ with peginterferon (pegIFN) and ribavirin (3). Over the past few years, specific antiviral agents have been developed to directly inhibit viral replication and are characterized as 'direct antiviral agents' (DAAs). Protease inhibitors (PI), such as boceprevir and telaprevir, in combination with pegIFN and ribavirin, have been associated with improved SVR to $60 \%$ to $70 \%$ in treatment-naive patients $(4,5)$. Improvements in HCV treatment have prompted the Centers for Disease Control and Prevention (Georgia, USA) to recommend one-time
}

\author{
L'hépatite C chronique dans l'Ouest canadien : un \\ sondage des profils de pratique chez les \\ gastroentérologues de l'Alberta et de la Colombie- \\ Britannique
}

OBJECTIF : Sonder les gastroentérologues de la Colombie-Britannique et de l'Alberta quant à leurs connaissances de la prise en charge du virus de l'hépatite $\mathrm{C}$ (VHC) chronique et des profils de pratique à cet égard chez les médecins qui soignent ou non des patients infectés par le VHC.

MÉTHODOLOGIE : Les gastroentérologues pour adultes en exercice de la Colombie-Britannique et de l'Alberta ont reçu un sondage anonyme de deux pages par la poste. Chez les médecins qui soignaient des patients atteints du VHC, les chercheurs ont examiné l'évaluation du prétraitement de la fibrose, la mesure de la réponse virologique rapide, la prescription des inhibiteurs de la protéase (IP), les obstacles à l'utilisation de ces agents et les profils d'aiguillage. Chez ceux qui ne traitaient pas le VHC, ils ont évalué l'aiguillage des patients en vue du traitement et la personne vers qui ils les aiguillaient.

RÉSULTATS : Soixante-dix-sept des 166 individus ont rempli le sondage (taux de réponse de $46 \%$ ). La plupart (49\%) exerçaient dans un établissement universitaire ou un grand établissement général (42\%). Les maladies hépatiques chroniques représentaient moins de $25 \%$ de la pratique individuelle de $71 \%$ des répondants. Ainsi, 48 (62\%) traitaient le VHC et les deux tiers prescrivaient un IP. Les obstacles à la prescription incluaient le manque de connaissances (six sur 16), le manque de professionnels paramédicaux (cinq sur 16) et le peu de patients dont le profil convenait (sept sur 16). Au total, $33 \%$ (16 sur 48) avaient effectué une biopsie hépatique avant le traitement, et $69 \%$ (33 sur 48) privilégiaient des mesures non effractives. De plus, $83 \%$ (40 sur 48 ) mesuraient la réponse virologique rapide. Les profils d'aiguillage avaient changé chez $46 \%$ (22 sur 48) des médecins qui traitaient le VIH. Tous les répondants qui ne traitaient pas cette maladie aiguillaient les patients pour les faire évaluer, et $90 \%$ (26 sur 29) les aiguillaient vers des hépatologistes.

CONCLUSIONS : Les maladies hépatiques chroniques représentaient moins de $25 \%$ de la pratique de la majorité des répondants. Parmi ceux qui traitaient le VIH, le tiers n'avait pas prescrit d'IP. Ceux qui traitaient des patients ayant une infection par le VHC constataient les obstacles à la prescription et les modifications au profil d'aiguillage.

screening for individuals born between 1945 and 1965 (6). These new agents, however, are associated with an increased burden of adverse drug effects, drug-drug interactions and complexity of administration protocols. Moreover, the plethora of DAAs in development will greatly add to the choice of available agents in the future, which may lead to uncertainty among clinicians as to which agents are best in a given situation.

In terms of attitudes and practice of clinicians, a previous pre-DAA Canadian survey reported heterogeneity of HCV practice patterns; however, most respondents appeared to adhere to Canadian Association for the Study of the Liver guidelines (7). A recent survey study from the United States (8) suggested that the introduction of newer agents may increase referral to liver specialists. Since the introduction of DAAs, there has been no recent Canadian survey to assess patterns of

Divisions of Gastroenterology, ${ }^{1}$ University of British Columbia, Vancouver, British Columbia; ${ }^{2}$ University of Calgary, Calgary; ${ }^{3}$ University of Alberta,

Edmonton, Alberta

Correspondence: Dr Eric M Yoshida, Division of Gastroenterology, University of British Columbia, Diamond Health Care Centre,

5153-2775 Laurel Street, Vancouver, British Columbia V5Z 1M9. Telephone 604-875-5371, fax 604-875-5447, e-mail eric.yoshida@vch.ca

Received for publication August 25, 2013. Accepted September 15, 2013 


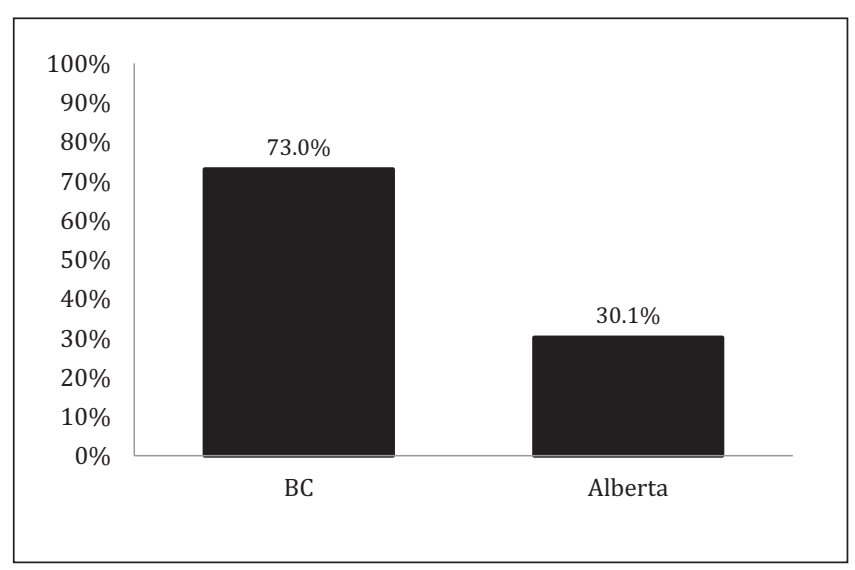

Figure 1) Response rate among gastroenterologists in British Columbia (BC) and Alberta

\section{TABLE 1}

Demographic data among gastroenterologists in British Columbia and Alberta $(n=77)$

\begin{tabular}{lc}
\hline Years of practice, $\mathrm{n}$ (range) & $14.2(1-46)$ \\
Treat hepatitis C virus infection & $48(62)$ \\
Guideline awareness & $62(81)$ \\
Protease inhibitor awareness & $72(94)$ \\
Pharmacare should cover & $74(96)$ \\
\hline
\end{tabular}

Data presented as $n(\%)$ unless otherwise indicated

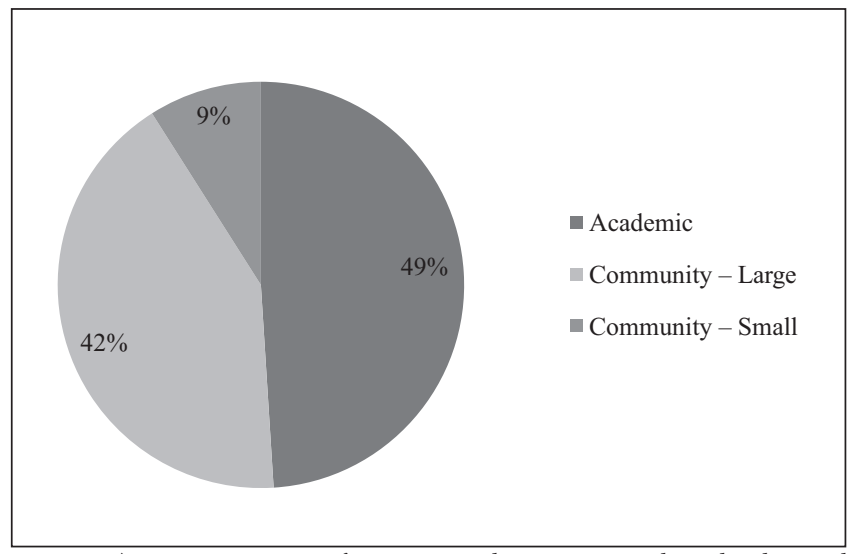

Figure 2) Practice setting of gastroenterologists in British Columbia and Alberta $(n=77)$

current practice, clinical attitudes and referral to liver specialists. To determine current attitudes and practice in the era of the new HCV therapies, a survey was distributed to all gastroenterologists in Western Canada (Alberta and British Columbia [BC]) to gather further insight into this matter.

\section{METHODS}

A two-page anonymous survey was distributed to all gastroenterologists in Alberta and $\mathrm{BC}$ and returned via fax. Participants were reminded midway through the study via e-mail as a second request to complete the survey. Completion of survey collection was on August 15, 2012 and basic descriptive statistics were performed. Compilation of all gastroenterologists in $\mathrm{BC}$ and Alberta was based on registration through the BC College of Physicians and Surgeons and Alberta College of Physicians and Surgeons, respectively, as of May 1, 2012. Individuals practicing in pediatric gastroenterology and gastroenterology trainees were not included. The study was approved by the University of British Columbia Research Ethics Board (Vancouver, BC).

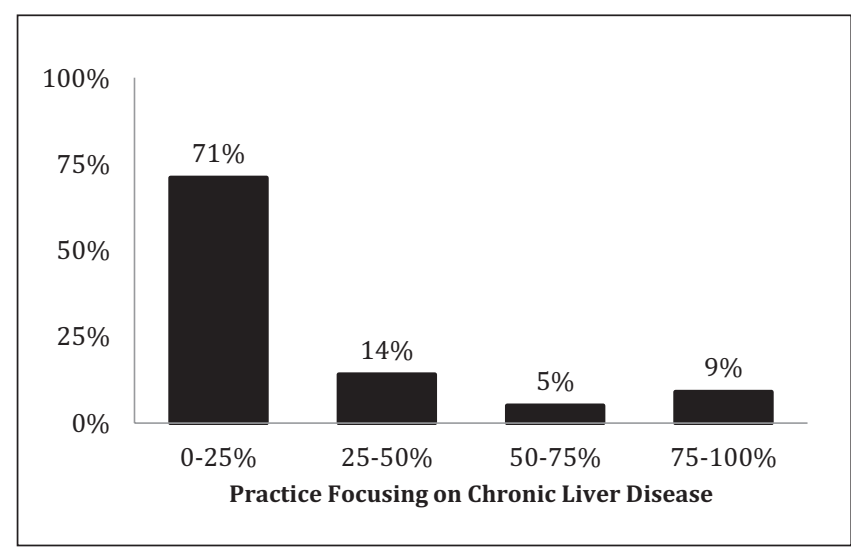

Figure 3) Percentage of practice focusing on chronic liver disease among all gastroenterologists $(n=77)$

\section{TABLE 2}

Practice patterns of physicians who treat hepatitis $C$ virus infection in British Columbia and Alberta $(n=48)$

\begin{tabular}{ll}
\hline Prescribed protease inhibitor & $32(67)$ \\
Liver biopsy before treatment & $16(33)$ \\
Noninvasive measures of fibrosis & $33(69)$ \\
Measure rapid virological response & $40(83)$ \\
\hline
\end{tabular}

Data presented as $n$ (\%)

\section{RESULTS}

The survey was distributed to 166 physicians, with 77 completed, corresponding to a response rate of $46 \%$. The response rate was higher in $\mathrm{BC}(73 \%)$ than in Alberta (30.1\%) (Figure 1). Based on demographic data (Table 1), the mean number of years of practice was 14.2 , with the majority $(49 \%)$ of respondents practicing in an academic centre or large community (42\%) (Figure 2).

Chronic liver disease comprised $<25 \%$ of practice in $71 \%$ of respondents (Figure 3). Fourteen per cent had practices in which chronic liver disease comprised $>50 \%$. Most $(81 \%)$ respondents were aware of Canadian HCV treatment guidelines (9) and 94\% were aware of PIs. Additionally, $96 \%$ agreed that BC Pharmacare or other provincial formularies should cover treatment for HCV infection. A total of 48 clinicians (62\%) treated patients with HCV infection (Table 1).

Among HCV treaters, only two-thirds have prescribed a PI. As part of pretreatment assessment, 33\% performed liver biopsy and 69\% are used noninvasive markers of fibrosis. Measurement of rapid virological response (RVR) was also used by $83 \%$ (Table 2). Among those who had not prescribed a PI, barriers to treatment (Figure 4) included few appropriate patients $(43.8 \%)$, lack of comfort prescribing newer agents $(37.5 \%)$ and inadequate allied health resources (ie, hepatitis nursing support) (31.3\%). Funding of treatment was less of a concern $(18.8 \%)$.

For those not treating $\mathrm{HCV}$, all respondents were referring their patients for consideration of therapy (29 of 29). The majority of referrals were to hepatologists $(90 \%)$, whereas infectious disease specialists and other clinicians were $7 \%$ and 3\%, respectively (Figure 5).

Referral pattern changes, for patients with HCV infection, had been noted in $46 \%$ of $\mathrm{HCV}$ treaters and only $10 \%$ of nontreaters (Figure 6).

\section{DISCUSSION}

The present study was the the first Canadian HCV practice survey since 2003 (7). At the time of distribution, the most recent Canadian guidelines were from 2007 (9), and the majority of survey respondents were aware of these. Since then, numerous DAAs have either been licensed or in clinical trials, and the landscape for treating 


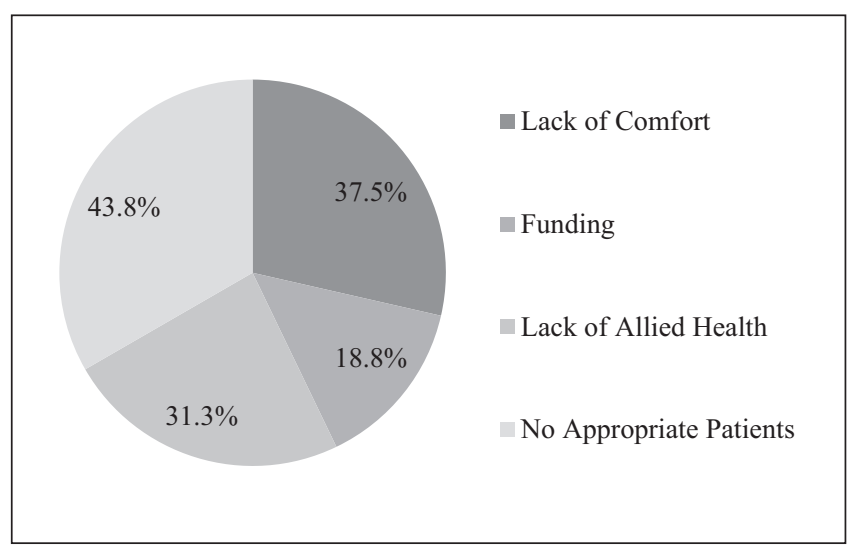

Figure 4) Barriers to prescription of protease inhibitors by physicians who treat hepatitis $\mathrm{C}$ patients but have not used them $(n=16)$

HCV - particularly genotype 1 - has changed. As a result, a consensus guidelines update was subsequently published in late 2012 (10). Overall, we found that chronic liver disease in general is not a significant component of a Western Canadian gastroenterologist's practice because $<30 \%$ of survey respondents had practices that included $>25 \%$ hepatology, although $62 \%$ of respondents identified themselves as $\mathrm{HCV}$ treaters. In this regard, our survey was not dissimilar to a 2003 survey (11) conducted by the Canadian Association of Gastroenterology that studied the pattern of practice in terms of hepatology among that organization's membership. In that survey, hepatology constituted only $10 \%$ of a Canadian gastroenterologist's practice, although $60 \%$ stated that they treated HCV infection. We suspect that the reported proportion of Western Canadian gastroenterologists who treat HCV is an over-representation because the response rate for the survey overall was $46 \%$, and clinicians who do not treat $\mathrm{HCV}$ are less likely to complete and return the survey, contributing to a selection bias.

Of those who identified themselves as HCV treaters, however, a surprising one-third had not prescribed a PI. Barriers, such as inadequate allied health care professional services (ie, hepatitis nursing) or inexperience with the newer agents, were a concern in approximately one-third of these individuals who had not prescribed a PI. Funding was a concern in only $18 \%$ and was not a significant barrier. With the rapid advancement of treatment complexity in HCV infection, the most recent guidelines acknowledge the need for multidisciplinary care and expert treaters, with increased resources directed to these groups (10). Interestingly, the most significant barrier to prescription was inappropriate patient profile. The exact reason is unclear, but possibilities would include decompensated cirrhosis at the time of referral for consideration, concurrent psychiatric, social or substance abuse problems or, less likely, a higher prevalence of HCV genotype 2 or 3 in the survey respondents' practice. Regardless, the relatively high proportion of current HCV treaters who are not prescribing a DAA suggests that in the future, with an increasing complexity of HCV protocols with the DAAs and the increasing number of DAAs on the market, this proportion will likely expand. The lack of availability of hepatitis nursing was recognized to be a significant obstacle to HCV treatment in the previous era of pegIFN and ribavirin dual therapy (12), the survey respondents have indicated that, in the era of DAAs, it will continue to be an obstacle.

In our survey, we asked two questions in an attempt to assess the interactions between provincially available diagnostic resources and clinical practice. The most recent guidelines suggest that before treatment, all patients should have severity of fibrosis assessed by either liver biopsy or a noninvasive measure. From our survey, only onethird of HCV treaters used liver biopsy, with $69 \%$ using noninvasive methods. Given the material risks of a liver biopsy, the transition to noninvasive diagnostic modalities is encouraging. Because these

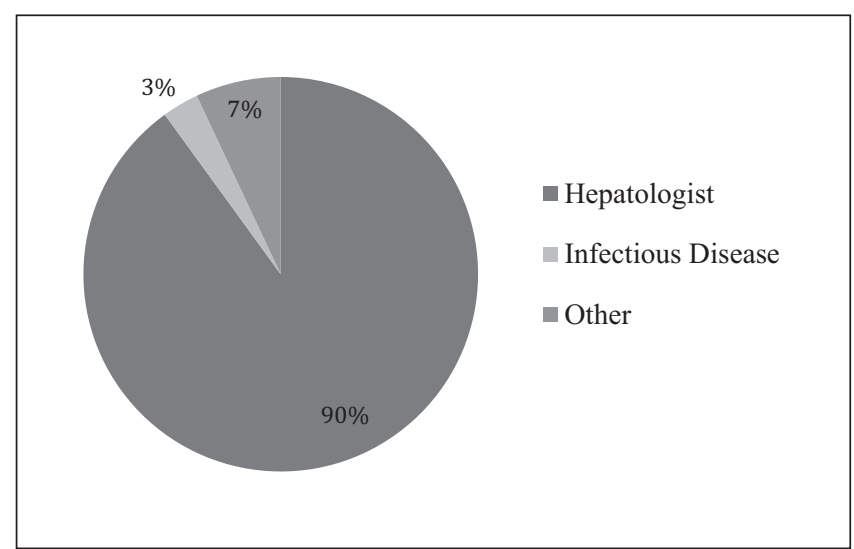

Figure 5) Referral patterns of physicians who do not treat hepatitis C infection $(n=29)$

noninvasive diagnostic modalities are not publically provided for in $\mathrm{BC}$ and can be very difficult to access in the community setting, we had expected the proportion of practitioners using core biopsies for fibrosis staging to have been higher. It is clear that the standard of care in Western Canada is to avoid invasive liver biopsies and this information can be used to advocate for public funding of Fibroscan (Echosens, France)/FibroTest (FibroSure, LabCorp, USA). We suspect that higher uptake of noninvasive methods will occur in the future, with decreased cost of resources and improved validation. Another issue is that of the RVR, specifically, the determination of HCV at week 4 of treatment. This measure emerged from the DAA trials and the literature suggests that it is one of the best predictors of treatment response and SVR (10). In the past, there have been local concerns that the turnover of the provincial virological laboratories would not allow the timely determination of HCV status at week 4 or that budgetary constraints would curtail this practice. Our survey revealed that while on treatment, $83 \%$ of clinicians treating HCV are measuring RVR. This indicates that laboratory resources in this area are not restricting clinical practice in the treatment of $\mathrm{HCV}$ infection.

In terms of those who are not treating HCV infection, $100 \%$ are referring these patients to other specialists for treatment. Although we are not certain of the referral patterns of those who did not respond to the survey, of the survey respondents, most (90\%) of the referrals were to hepatologists, with only a small number referring to infectious disease specialists or general internists. Given the relatively small number of hepatologists in Western Canada and the potential increase in referral volume of $\mathrm{HCV}$ patients, we suggest that more training in $\mathrm{HCV}$ management, either as part of the core gastroenterology training or as part of a formal hepatology training, will be needed in the future; otherwise, patients with HCV infection may have difficulty accessing appropriate therapy.

Referral patterns from primary care physicians/specialists have also been affected, although the impact has been primarily on those treating HCV. This is not surprising because increased awareness of treatment in popular culture, as well as referrals from individuals not experienced in the prescription of PI, likely contribute. Presently, there are no screening recommendations in Canada; however, referral patterns would be expected to increase if a program was implemented. In the United States, the Centers for Disease Control and Prevention has recently published recommendations for screening the 'baby boomer' cohort who were born between 1945 and 1965 (13). The US Preventive Services Task Force (14) has also recommended screening for HCV. We expect that with increased screening, more patients will come forward for HCV treatment, especially given the superior outcomes with DAAs. 


\section{CONCLUSION}

In our survey of Western Canadian gastroenterologists, chronic liver disease constituted $<25 \%$ of practice in a vast majority, indicating that a dedicated hepatology practice is comparatively rare. Despite this, $62 \%$ identified themselves as HCV treaters, yet one-third did not prescribe the new PI, suggesting that the proportion of $\mathrm{HCV}$ treaters in the future may diminish as DAAs become the dominant HCV treatment. Lack of hepatitis nursing support was identified as a factor in the decision not to prescribe DAAs by the survey respondents. It is also clear from our survey that noninvasive modalities of staging for fibrosis is the standard of care in $\mathrm{BC}$ and Alberta despite the fact that there is no public funding for these modalities in $\mathrm{BC}$. Given the referral patterns of those not treating $\mathrm{HCV}$, it is clear that expanding the training of $\mathrm{HCV}$ treatment in the future will be a necessity.

ACKNOWLEDGEMENT: The authors thank Ms Jo-Ann Ford and the research staff of the BC Hepatitis Program of the Vancouver General Hospital for collecting the study data and assisting with the logistics of this study project. They also thank Hoffman LaRoche Canada for providing an unrestricted research grant to assist with the expenses associated with this project.

\section{REFERENCES}

1. Public Health Agency of Canada. <www.phac-aspc.gc.ca/hepc/ index-eng.php $>$ (Accessed August 4, 2013).

2. Ghany MG, Strader DB, Thomas DL, Seeff LB, American Association for the Study of Liver Disease. Diagnosis, management, and treatment of hepatitis C: An update. [Practice Guideline.] Hepatology 2009;49:1335-74.

3. Hoofnagle JH, Seeff LB. Peginterferon and ribavirin for chronic hepatitis C. N Engl J Med 2006;355:2444-51.
4. Jacobson IM, McHutchison JG, Dusheiko G, et al. Telaprevir for previously untreated chronic hepatitis $\mathrm{C}$ virus infection. N Engl J Med 2011;364:2405-16.

5. Poordad F, McCone J, Bacon BR, et al. Boceprevir for untreated chronic HCV genotype 1 infection. N Engl J Med 2011;364:1195-206.

6. CDC. Recommendations for the identification of chronic hepatitis $\mathrm{C}$ virus infection among persons born during 1945-1965. MMWR 2012;61(No. RR-4).

7. Wang P, Yi Q, Scully L, Heathcote J, Krahn M. Indications for interferon/ribavirin therapy in hepatitis $\mathrm{C}$ patients: Findings from a survey of Canadian hepatologists. CanJ Gastroenterol 2003;17:183.

8. Gaglio PJ, Moss N, McGaw C, Reinus J. Direct-acting antiviral therapy for hepatitis C: Attitudes regarding future use. Dig Dis Sci 2011;56:1509-15.

9. Sherman M, Shafran S, Burak K et al. Management of chronic hepatitis C: Consensus guidelines. Can J Gastroenterol 2007;21(Suppl C):25-34.

10. Myers RP, Ramji A, Bilodeau M, Wong, S, Feld JJ. An update on the management of chronic hepatitis $\mathrm{C}$ : Consensus guidelines from the Canadian Association for the Study of the Liver. Can J Gastroenterol 2012;26:359-75.

11. Bain VG, Wong WW, Greig PD, Yoshida EM. Hepatology and the Canadian gastroenterologist: Interest, attitudes and patterns of practice: Results of a national survey for the Canadian Association of Gastroenterology. Can J Gastroenterol 2003;17:25-9.

12. Ford JA, Cheong-Lee C. The role of hepatology nurse in the difficult-to-treat hepatitis C population. Can J Gastroenterol 2007;21:353-4.

13. Smith BC, Morgan RL, Beckett GA et al. Hepatitis $C$ virus testing of persons born during 1945-65: Recommendations from the Centre for Disease Control and Prevention. Ann Intern Med 2012;157:817-22

14. US Preventive Services Task Force. Screening for hepatitis C virus infection in adults. <www.uspreventiveservicestaskforce.org/ uspstf12/hepc/hepcfinalrs.htm> (Accessed August 4, 2013). 


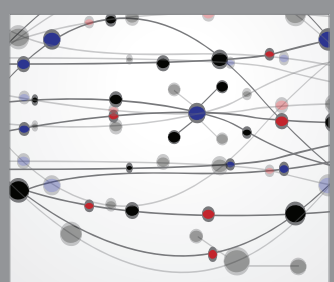

The Scientific World Journal
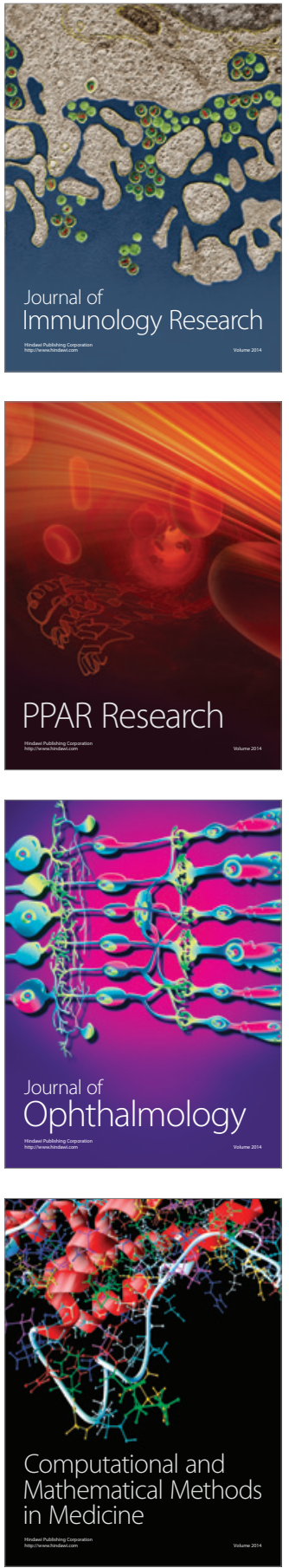

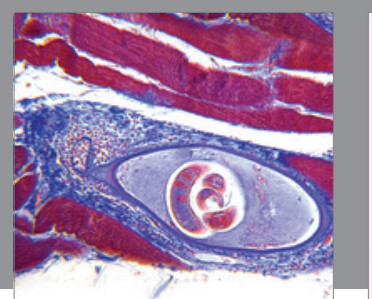

Gastroenterology Research and Practice

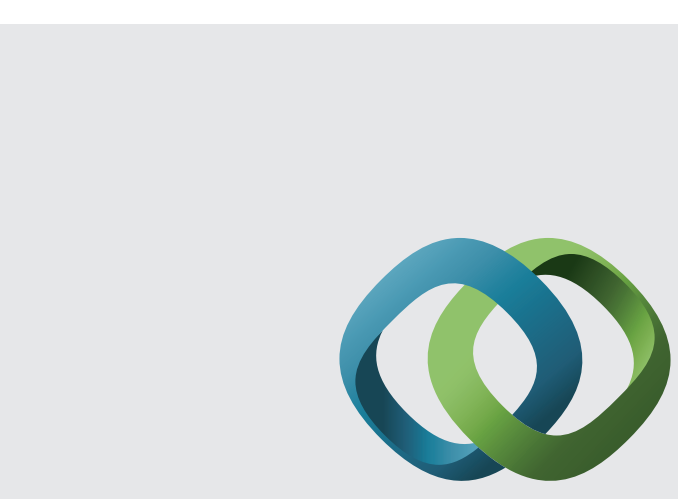

\section{Hindawi}

Submit your manuscripts at

http://www.hindawi.com
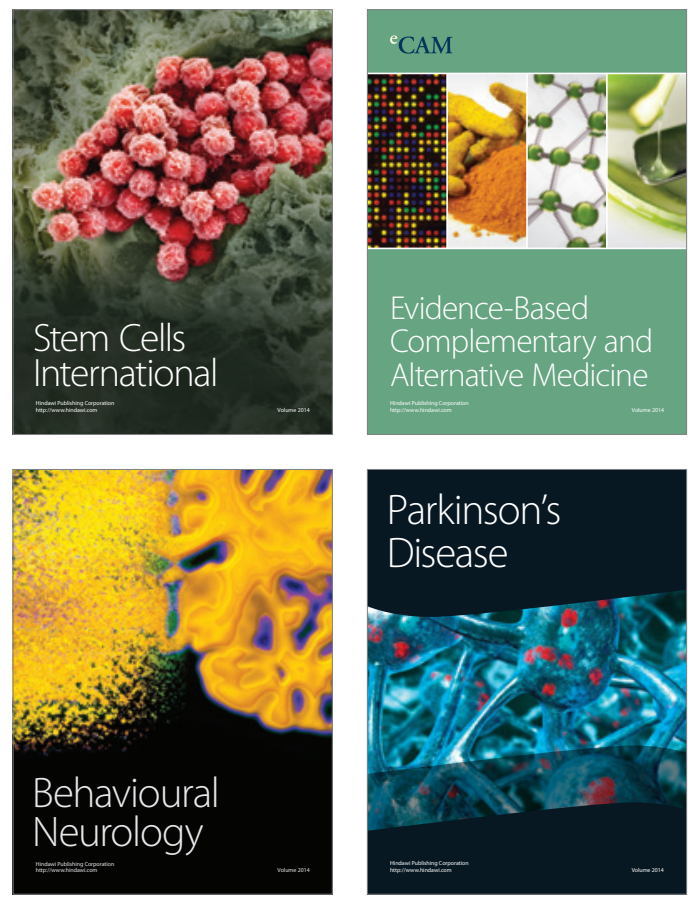
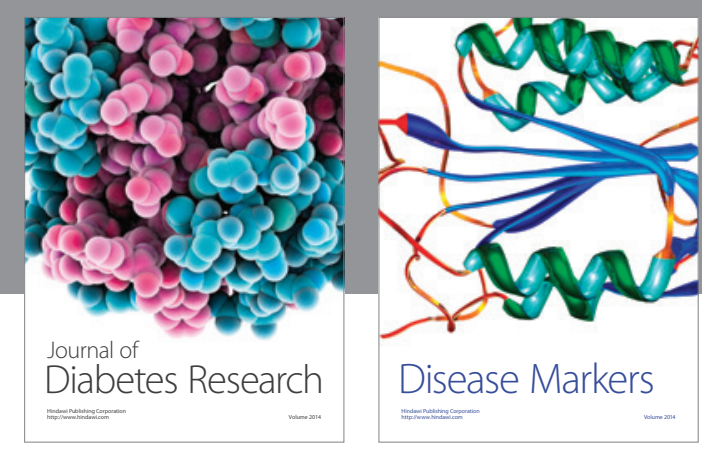

Disease Markers
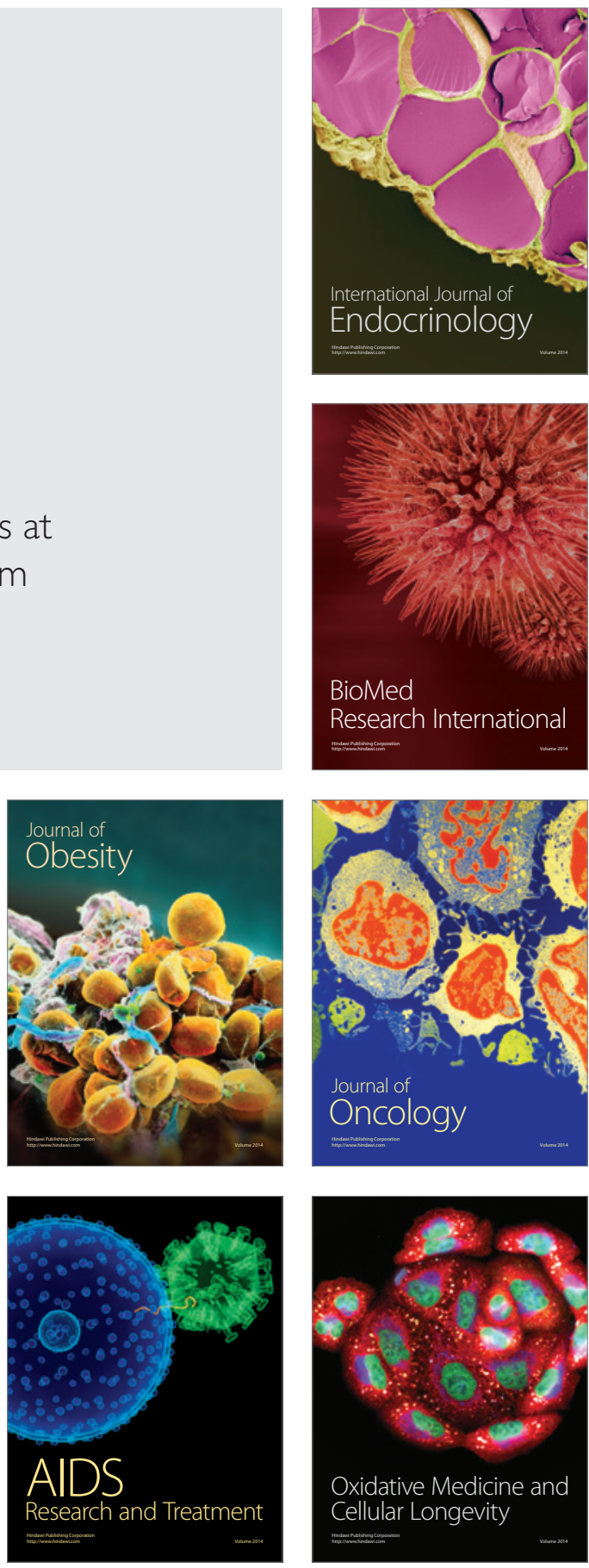